OPEN ACCESS

Edited by:

Peng He,

Guizhou University, China

Reviewed by:

Jin Zhang,

Max-Planck-Institut für chemische

Ökologie, Germany

Ya-Nan Zhang,

Huaibei Normal University, China

${ }^{*}$ Correspondence:

Ming-Jing Qu

13455277580@163.com

tThese authors have contributed equally to this work and should be considered first co-authors.

Specialty section:

This article was submitted to

Invertebrate Physiology,

a section of the journal

Frontiers in Physiology

Received: 05 December 2017 Accepted: 01 June 2018

Published: 18 July 2018

Citation:

Ju Q, Li X, Guo X-Q, Du L, Shi C-R and Qu M-J (2018)

Two Odorant-Binding Proteins of the Dark Black Chafer (Holotrichia parallela) Display Preferential Binding to Biologically Active Host Plant Volatiles. Front. Physiol. 9:769. doi: 10.3389/fphys.2018.00769

\section{Two Odorant-Binding Proteins of the Dark Black Chafer (Holotrichia parallela) Display Preferential Binding to Biologically Active Host Plant Volatiles}

\author{
Qian Jut, Xiao Lit, Xiao-Qiang Guo, Long Du, Chen-Ren Shi and Ming-Jing Qu* \\ Shandong Peanut Research Institute, Qingdao, China
}

The dark black chafer (DBC), Holotrichia parallela, is an important pest of multiple crops. Insect host-searching behaviors are regulated by host plant volatiles. Therefore, a better understanding of the mechanism linking the chemosensory system to plant volatiles at the molecular level will benefit DBC control strategies. Based on antenna transcriptome data, two highly expressed antenna-specific odorant-binding proteins (HparOBP20 and 49) were selected to identify novel DBC attractants using reverse chemical ecology methods. We expressed these proteins, mapped their binding specificity, and tested the activity of the plant volatiles in the field. The ligands used in the binding specificity assays included 31 host-plant-associated volatiles and two sex pheromone components. The results showed that (1) HparOBP20 and 49 are involved in odor recognition; (2) these proteins bind attractive plant volatiles strongly and can therefore be employed to develop environmentally friendly DBC management strategies; and (3) the green-leaf volatile (Z)3-hexenyl acetate shows a high binding affinity to HparOBP20 $(\mathrm{Ki}=18.51 \mu \mathrm{M})$ and HparOBP49 $(\mathrm{Ki}=39.65 \mu \mathrm{M})$ and is highly attractive to DBC adults, especially females. In the field test, a (Z)-3-hexenyl acetate trap caught an average of $13 \pm 1.202$ females per day, which was significantly greater than the corresponding male catch $(F 2,6=74.18$, $P<0.0001$ ). (Z)-3-Hexenyl acetate may represent a useful supplement to the known sex pheromone for DBC attraction. In the present study, the binding characteristics of two HparOBPs with host plant volatiles were screened, providing behaviourally active compounds that might be useful for DBC control, based on reverse chemical ecology.

Keywords: Holotrichia parallela, odorant-binding proteins, host plant volatiles, reverse chemical ecology, (Z)-3-hexenyl acetate

\section{INTRODUCTION}

The dark black chafer (DBC), Holotrichia parallela Motschulsky (Coleoptera: Scarabaeidae), is an important pest in agriculture and forestry. DBC larvae, often referred to as grubs, live in soil and can cause significant damage to peanut, sweet potato, soybean, corn, and various other vegetable crops as well as to turf and ornamental species (Ju et al., 2012; Shan et al., 2014). Due to its cryptic and subterranean nature, this beetle is difficult to control. The main tactic employed for DBC 
management is chemical control, which has environmentally detrimental consequences, such as residual toxicity, environmental contamination, and insecticide resistance. Mass trapping using sex pheromone-based attractants is an environmentally friendly control tactic and has become well established. However, this tactic has several shortcomings, including a male response bias to the sex pheromone traps and a short duration of residual activity (Reddy and Guerrero, 2004; Said et al., 2005). Similar to insect pheromones, plant volatiles are important signaling compounds that regulate insect behavior and exhibit potential as natural pesticides, lures, or antifeedants (Hanks et al., 2012; Hanks and Millar, 2013; Jung et al., 2013; Collignon et al., 2016; Wang F. et al., 2016; Wang Y.L. et al., 2016). Therefore, studies addressing the physiological and molecular basis of host plant selection could serve as an important basis for developing novel control tactics for the DBC (Koczor et al., 2012).

The interaction between plant volatiles and the insect olfactory system plays a critical role in the initial step of insect host orientation (Liu et al., 2015; Brito et al., 2016; Sun et al., 2017a). Plant volatiles consist of various classes of chemicals, such as green-leaf volatiles, general odorants and terpenoids (Aartsma et al., 2017). Due to the great diversity of plant volatiles, behavioral response methods for selecting active host plant volatiles require a great deal of time and effort. In this context, the reverse chemical ecology approach is gaining importance (Mao et al., 2010; Jayanthi et al., 2014), as it narrows down the number of odorant candidate compounds based on their binding affinity to olfactory proteins, saving time and reducing research costs compared with conventional trial-and-error screening performed in the field (Leal, 2017). Odorant-binding proteins (OBPs) are one of the major types of peripheral olfactory proteins involved in the reception of odorants in insects (Vogt et al., 1985; Klein, 1987; Leal, 2013). The physiological functions of insect OBPs have been described based on biochemical, biophysical, structural biology and kinetic studies (Sandler et al., 2000; Horst et al., 2001; Leal et al., 2005; Zhu et al., 2017), and it is clear that OBPs are important for transporting odorants through the sensillar lymph and increase the sensitivity of the olfactory system (Pelosi et al., 2014; Leal, 2017). The role of OBPs in the transport of molecules in insect antennae was described for the first time in Lepidoptera using male Antheraea polyphemus antennae (Vogt and Riddiford, 1981). Knockdown studies have demonstrated that DmelOBP76a (LUSH) is necessary for the olfactory process in Drosophila melanogaster (Xu et al., 2005; Laughlin et al., 2008). Furthermore, behavioural assays in Drosophila mutants (Matsuo et al., 2007; Swarup et al., 2011) and aphids (Qiao et al., 2009; Sun et al., 2012) have indicated that OBPs are involved in semiochemical detection. Previous studies have shown that a blend of volatiles derived from host plants can bind to OBPs and be used as a luring agent. A good example is provided by Loxostege sticticalis OBP2, which has been shown to exhibit a high affinity to host plant volatiles (Yin et al., 2012). OBP1 of Grapholita molesta exhibits dual functions in the recognition of host plant volatiles (Li et al., 2016). Two Spodoptera exigua OBPs share a common odorantresponse spectrum, with a considerable binding affinity to host odorants (Liu et al., 2017). Binding assays of two OBPs from
H. oblita with various compounds showed that benzoates (leaf volatiles from host plants) fit inside the OBPs (Deng et al., 2012).

However, little is known about the molecular mechanisms underlying the interactions between DBCs and the odorous environment of their host plants. To date, only one report has described the binding functions of two OBPs in the DBC (Ju et al., 2012). Using a rapid amplification of cDNA ends (RACE) approach, the HparOBP1 and HparOBP2 genes were identified, and their ligand-binding properties were examined. Due to recent transcriptome projects, a large number of insect OBP sequences are available. Additionally, 25 OBP genes were obtained from the DBC whole-body transcriptome (Ju et al., 2014). However, the OBPs predicted from insect whole-body genomes are all unlikely to represent true olfactory proteins. In D. melanogaster, for instance, the OBP gene family comprises as many as 51 putative OBPs, but only seven of them have been demonstrated to be expressed specifically in adult olfactory organs (Galindo and Smith, 2001). At present, investigation of the antennal transcriptome is an effective way to find functional OBPs binding to plant volatiles. In this study, we identified the OBP genes expressed in DBC antennae using the transcriptome sequencing approach. Two HparOBPs were selected based on their specific phylogenetic position and antenna-specific expression pattern to determine their ligand-binding properties. Furthermore, the attractive properties of ligands binding to the two HparOBPs were verified in behavioral responses tests and field evaluations. Taken together, our results extend the knowledge of OBP genes in the DBC and pave the way for the development of novel environmentally friendly control tactics for DBC management.

\section{MATERIALS AND METHODS}

\section{Insects and Insect Maintenance}

Adults DBCs were collected from the field of the experimental station at Shandong Peanut Research Institute, Qingdao, China. The beetles were separated into males and females and were reared with fresh elm tree (Ulmus pumila L.) leaves in a rotating chamber with aerating meshes. The relative humidity in the rearing chamber was maintained at $18-20 \%$. Fresh antennae were obtained from both males and females for experimentation.

\section{Transcriptome Sequencing}

Total RNA was isolated from adult antennae ( $\sim 200$ antennae from both males and females). The RNA was quantified using a NanoDrop spectrophotometer (Thermo, Franklin, TN, United States). The mRNA was subsequently used for cDNA synthesis as described by Rice et al. (2000). cDNA synthesis, library construction and sequencing, gene annotation and prediction, and OBP identification and confirmation were conducted as described in previous articles (Ju et al., 2014). Briefly, the double-stranded cDNAs were fragmented into segments of 300-500 bp via sonication, and the sonicated mixture was purified using Agencourt-AMPure beads (Beckman, Schaumburg, IL, United States). A cDNA library was then generated using the TruSeq ${ }^{\mathrm{TM}}$ RNA Sample Prep Kit (Illumina, San Diego, CA, United States). The cDNA library was 
subsequently sequenced on the Illumina HiSeq 4000 sequencing platform. Raw read quality was assessed using FastQC ${ }^{1}$ prior to assembly, and Trimmomatic was used to filter adaptor sequences and trim reads bases with a PHRED quality score below 20. After adaptor filtering, the resulting reads were de novo assembled into contigs using the Trinity program. The 'align and estimate abundance' script in the Trinity package was used to align the reads and perform transcript abundance estimation using the RSEM method. The assembled contigs were further clustered using the TGI Clustering Tool (Pertea et al., 2003).

\section{RNA Isolation, CDNA Synthesis, and PCR Cloning}

The cloning primers were designed using Primer Express 3.0 and are listed in Supplementary Table S1. PCR was carried out in a total volume of $50 \mu \mathrm{l}$ containing $200 \mathrm{ng}$ of cDNA template, $5 \mu \mathrm{l}$ of $10 \times$ buffer, $4 \mathrm{mmol} / \mathrm{L} \mathrm{MgCl}_{2}, 0.8 \mu \mathrm{mol} / \mathrm{L}$ of each forward and reverse primer, $1 \mathrm{mmol} / \mathrm{L}$ dNTPs, and $2.5 \mathrm{U}$ of Taq polymerase. The PCR program started at $95^{\circ} \mathrm{C}$ for $5 \mathrm{~min}$ for denaturation, followed by 25 cycles of $30 \mathrm{~s}$ at $95^{\circ} \mathrm{C}, 30 \mathrm{~s}$ at $60^{\circ} \mathrm{C}$, and $30 \mathrm{~s}$ at $72^{\circ} \mathrm{C}$, with a final extension at $72^{\circ} \mathrm{C}$ for $5 \mathrm{~min}$.

\section{Phylogenetic Analysis}

Both the novel OBP genes identified in this study and the reported OBP gene sequences retrieved from previous studies were included in the phylogenetic analysis (Ju et al., 2014; Li X. et al., 2015). Multiple alignments of OBP genes were generated using MAFFT alignment software version 7.215 (Katoh et al., 2009). Based on the capability for parallelizing computation, the IQ-TREE program version 1.5 was employed to construct a phylogenetic tree using the protein sequences of these OBP genes according to the maximum likelihood principle (Lam-Tung et al., 2015). The best protein substitution model was selected by the built-in model-selection function of the IQ-TREE program, and bootstrap support values from 1000 replicates were assessed with ultrafast bootstrap approximation.

\section{Fluorescence Competitive Binding Assay}

Recombinant protein expression and purification were performed according to our previously reported protocols (Ju et al., 2012). Briefly, plasmid constructs containing the HparOBP genes were generated and transformed into Rosetta (DE3) competent cells for recombinant protein expression, and the resulting proteins were highly induced with $1 \mathrm{mM}$ isopropyl $\mathrm{B}$-D-1-thiogalactopyranoside (IPTG) for $3-6 \mathrm{~h}$ at $37^{\circ} \mathrm{C}$. Purification was performed via $\mathrm{Ni}$ ion affinity chromatography (GE Healthcare, Beijing, China), and the His-tag was removed using enterokinase for HparOBP20 or tobacco etch virus (TEV) protease for HparOBP49. Renaturation and extensive dialysis were performed as previously reported (Ju et al., 2012), and the size and purity of the recombinant proteins were verified through SDS-PAGE.

For the ligand-binding assays, 33 compounds ( $>95 \%$ purity, Sigma-Aldrich, Shanghai, China) were selected based on their

\footnotetext{
${ }^{1}$ http://www.bioinformatics.babraham.ac.uk/projects/fastqc
}

previously reported isolation from DBC host plants (Cheng et al., 2010; Lee et al., 2010; Shi et al., 2011; Ju et al., 2012; Tang et al., 2012; Iqbal et al., 2014). We used an F-380 fluorescence spectrophotometer (Tianjin, China) to determine the results of the perform the binding assay at room temperature $\left(25^{\circ} \mathrm{C}\right)$. The excitation wavelength was $337 \mathrm{~nm}$, and the emission spectrum was recorded between 390 and $460 \mathrm{~nm}$. N-phenyl1-naphthylamine (1-NPN) is an effective fluorescent probe for insect OBP binding studies. First, we measured the constant emission of HparOBPs with 1-NPN, and titrated $2 \mu \mathrm{M}$ proteins in $50 \mathrm{mM}$ Tris- $\mathrm{HCl}(\mathrm{pH}$ 7.4) with $1 \mathrm{mM} \mathrm{1-NPN}$ in methanol to final concentrations ranging from 1 to $24 \mu \mathrm{M}$. Then, the affinities of other ligands were tested in competitive binding assays using 1-NPN as a fluorescent reporter at a concentration of $2 \mu \mathrm{M}$, while the concentration of each competitor ranged from 2 to $30 \mu \mathrm{M}$. We evaluated each bound chemical based on its fluorescence intensity, with the assumption that the protein was $100 \%$ active of 1:1 (protein/ligand) saturation. The binding curves were linearized using a Scatchard plot, and the dissociation constants of the competitors were calculated from the Scatchard plot of the binding data and the corresponding IC50 values based on the following equation: $\mathrm{Ki}=\left[\mathrm{IC}_{50}\right] /(1+[1-$ $\mathrm{NPN}] / \mathrm{K}_{1-\mathrm{NPN}}$ ), where [1-NPN] is the free concentration of $1-\mathrm{NPN}$, and $\mathrm{K}_{1-\mathrm{NPN}}$ is the dissociation constant of the complex protein/1-NPN.

\section{Electroantennogram (EAG) and Olfactory Response Assays}

The biologically attractive effects of chemicals with an ability to bind HparOBPs strongly were tested.

The EAG responses of virgin male/female antennae were measured after removing the tips of the three antennal lamellae (at approximately $1 \mathrm{~mm}$ ) and separating them from each other. The chemicals used for the EAG and behavior assays were diluted in methanol (HPLC grade) to varying concentrations $(0.1,1$, and $10 \mu \mathrm{g} / \mu \mathrm{l})$, and methanol was used as a control. A $10 \mu \mathrm{l}$ aliquot of each concentration was applied to a filter paper $(25 \times 8 \mathrm{~mm})$. EAG responses were recorded for $5 \mathrm{~s}$, with a stimulation interval of $30 \mathrm{~s}$ and a flow rate of $4 \mathrm{ml} / \mathrm{s}$ for both the stimulant and purge airflow. Each chemical was tested against six antennae, and each antenna was tested with three repeated stimulations. The EAG apparatus consisted of a signal acquisition system (IDAC4), a micromanipulator assembly (INR-5), a stimulus controller (CS-05), and a system for outputting the EAG results (Syntech Company, Holland).

The behavioral responses of female and male adults to the putative ligands were tested using a Y-tube olfactometer in a dark room at $27 \pm 1^{\circ} \mathrm{C}$. A filter paper $(25 \times 8 \mathrm{~mm})$ with $10 \mu \mathrm{l}$ of the test compound was placed at the end of one arm of the Y-tube, with $10 \mu \mathrm{l}$ of methanol at the end of the other arm (control tube). The airflow was $500 \mathrm{ml} / \mathrm{min}$. Six replicates were performed for each stimulant with 10 healthy virgin adults in the main stem of the Y-tube, and 10 min was allowed for their distribution. The response rate was calculated according to the following equations: response rate $=(\mathrm{T}+\mathrm{C}) / \mathrm{SUM}$ and selective response rate $=\mathrm{T} /(\mathrm{T}+\mathrm{C})$, where $\mathrm{T}$ represents the number of 
Tree scale: 1

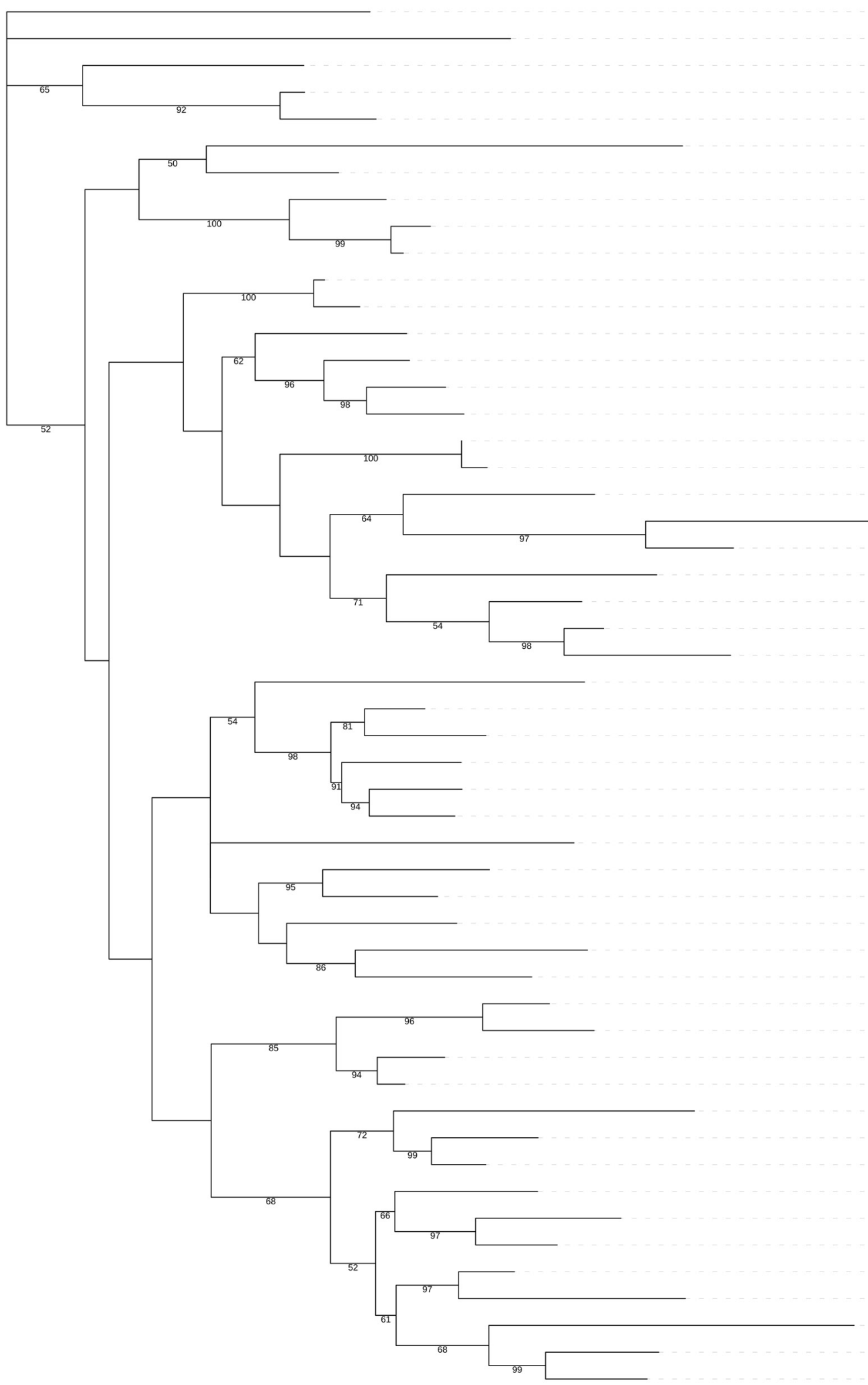

HparOBP43 (0.34)

HparOBP44 (0.24)

HparOBP47 (0.42)

HparOBP19 (397.66)

AcorOBP12

HparOBP37 (19.19)

HparOBP26 (1.19)

HparOBP5 (8.27)

AcorOBP5

HparOBP27 (19.54)

AcorOBP10

HparOBP10 (87.91)

HparOBP12 (0.01)

HparOBP25 (0.14)

AcorOBP9

AcorABP1

AcorOBP1

HparOBP38 (16894.05)

HparOBP28 (106.78)

HparOBP40 (4.51)

HparOBP42 (1.17)

HparOBP39 (2.51)

AcorOBP3

AcorOBP4

HparOBP4 (4030.55)

HparOBP41 (0.42)

HparOBP34 (14.54)

HparOBP33 (5.8)

HparOBP6 (88.68)

HparOBP36 (14.05)

HparOBP35 (163.54)

HparOBP45 (6.87)

HparOBP32 (8.55)

HparOBP11 (96.76)

HparOBP30 (19.01)

HparOBP29 (51.77)

HparOBP31 (75.04)

AcorOBP11

HparOBP14 (775.27)

AcorOBP13

HparOBP16 (793.23)

HparOBP46 (206.79)

AcorOBP6

HparOBP15 (27.83)

HparOBP49 (37123.69)

HparOBP13 (0.21)

AcorOBP15

HparOBP20 (3060.60)

HparOBP18 (0.93)

HparOBP21 (4.53)

AcorOBP8

AcorOBP7

FIGURE 1 | Phylogenetic tree of OBP genes in the DBC and A. corpulenta. The tree was constructed using IQ-TREE version 1.5. 


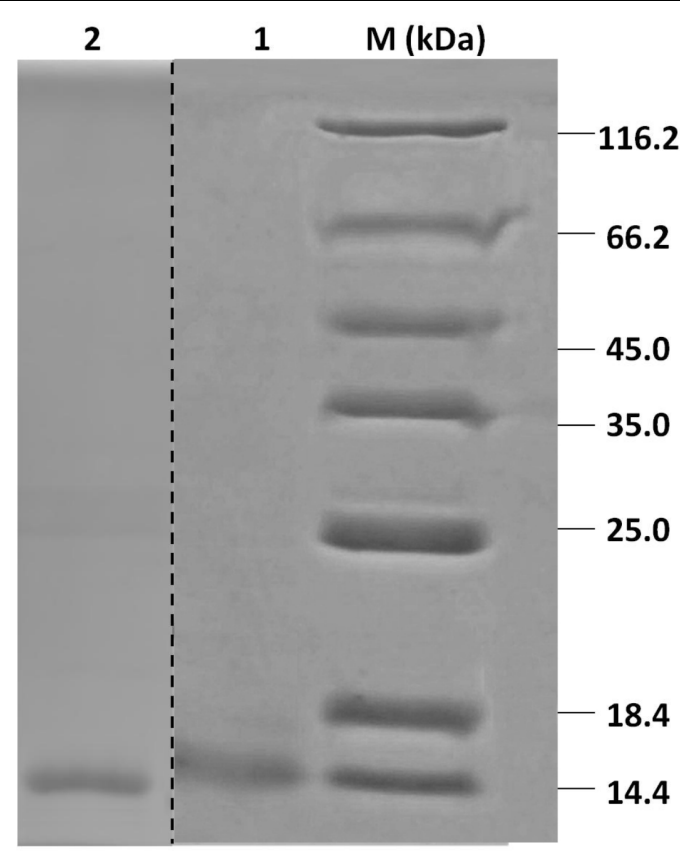

FIGURE 2 | SDS-PAGE analyses of HparOBP purification. Protein markers (M) are labeled with sizes on the left and right sides. Lanes 1 and 2 show the purified proteins HparOBP20 and HparOBP49.

beetles in the treatment tube; $\mathrm{C}$ indicates the number of beetles in the control tube; and SUM is the number of beetles tested.

\section{Field Evaluation}

According to the laboratory evaluation, in addition to the main sex pheromone component, L-leucine methyl ester, $(Z)$ 3-hexenyl acetate was considered as a candidate compound for attracting DBC adults in the field. The tested chemicals were individually dissolved with methanol to $360 \mathrm{mg} / \mathrm{ml}$. A dispenser was constructed using oil-free cotton wool with $360 \mathrm{mg}$ of the tested chemical and stored in a freezer before use. Methanol was employed as a control. The treatments were as follows:

- L-leucine methyl ester alone, $360 \mathrm{mg} / \mathrm{ml}, 1 \mathrm{ml} /$ dispenser - (Z)-3-hexenyl acetate alone, $360 \mathrm{mg} / \mathrm{ml}, 1 \mathrm{ml} /$ dispenser - methanol alone as control, 99\% purity, $1 \mathrm{ml} /$ dispenser

All experiments were performed at the experimental station of the Shandong Peanut Research Institute, Lai Xi Wang Cheng, Qingdao, China. Traps were placed in middle of the field, and each trap was located $60 \mathrm{~m}$ from any other trap, so that the individual treatments were $60 \mathrm{~m}$ apart. To avoid crosscontamination, only one compound was tested at each sub-site at any time, and each compound was tested at only one sub-site (Isberg et al., 2017). Each trap was set to operate from $1 \mathrm{~h}$ before sunset until $1 \mathrm{~h}$ after sunset. Three traps (replicates) were selected for each treatment. The test period was June 1-20, 2017. As a rule, the traps were checked every day, and the individuals that were caught in all experiments were sexed.
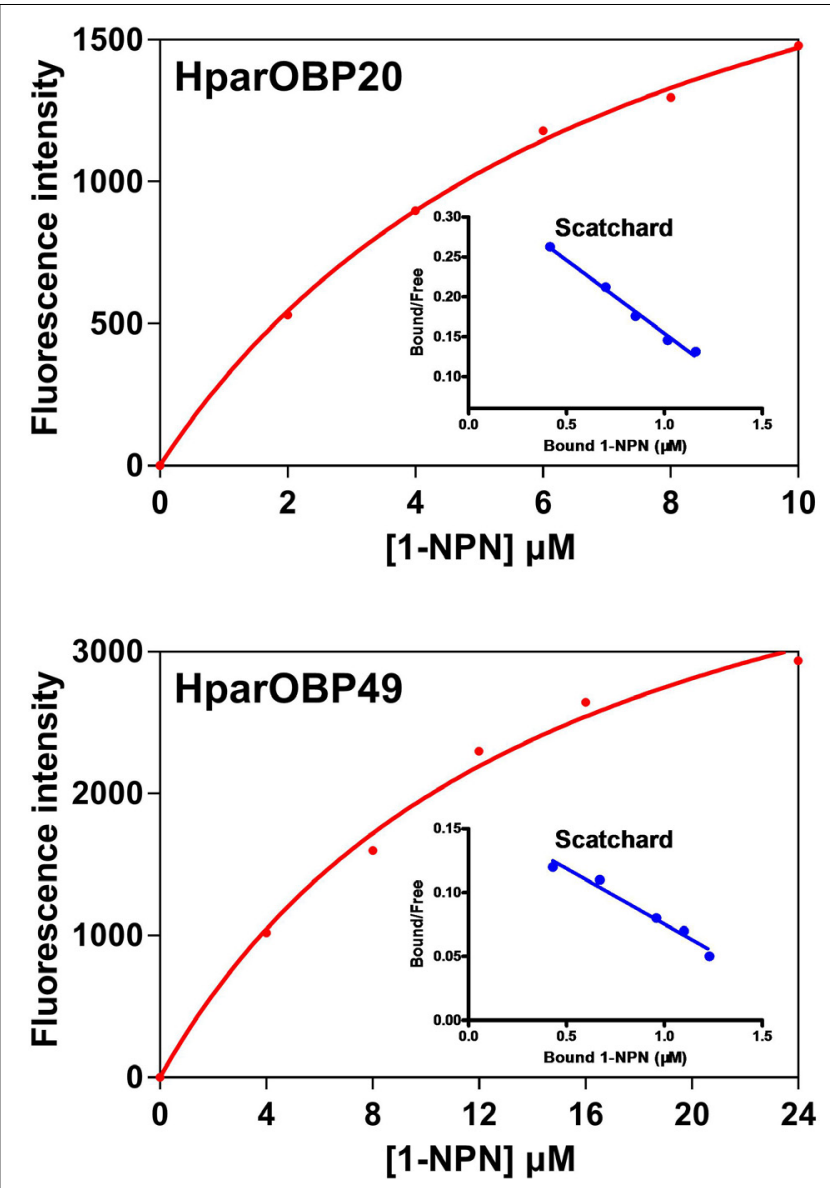

FIGURE 3 | Saturation binding curves and relative Scatchard plots of the affinity of 1-NPN to HparOBPs. The dissociation constants of 1-NPN with the HparOBPs were $7.439 \pm 1.45$ (HparOBP20) and $14.67 \pm 2.96$ (HparOBP49), respectively.

\section{RESULTS}

\section{Characterization of Antenna OBP-Encoding Genes}

A total of 30,338,129 paired-end reads were produced with a read length equal to 150 bp (Data Availability Statement: All the illumina sequencing data are available from the SRA database, accession number SRP148674). After low-quality filtering and adaptor cleaning, 30,297,575 filtered reads (representing 99.87\% of total raw reads) were used for de novo assembly, resulting in a total of 106,562 contigs with an N50 length of 1,351 bp. The metrics of the DBC transcriptome assemblies were compared with those of the pine shoot beetle transcriptome (Zhu et al., 2012). The quality of these two transcriptome assemblies was comparable, indicating that the DBC assembly was suitable for downstream transcriptome analyses.

\section{Phylogenetic Analysis}

A total of 48 HparOBP-encoding transcripts (containing 113223 amino acids) were identified through BLAST searches. The 


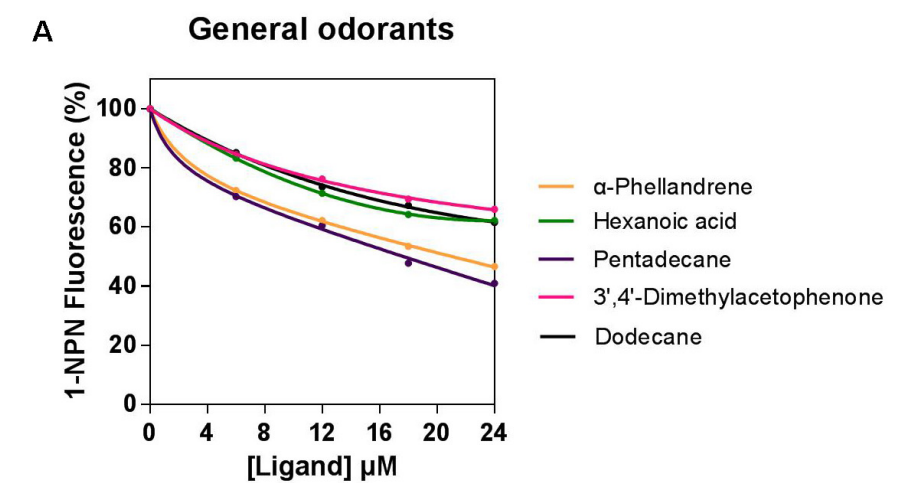

Terpenoids

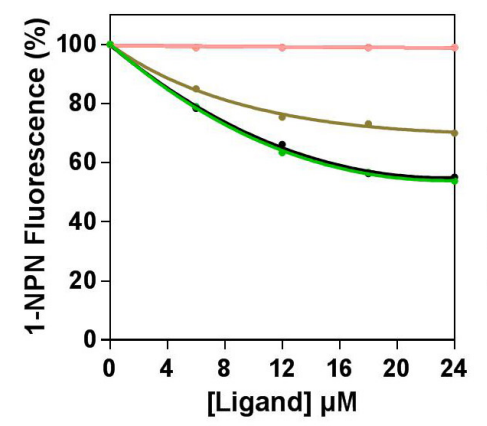

B

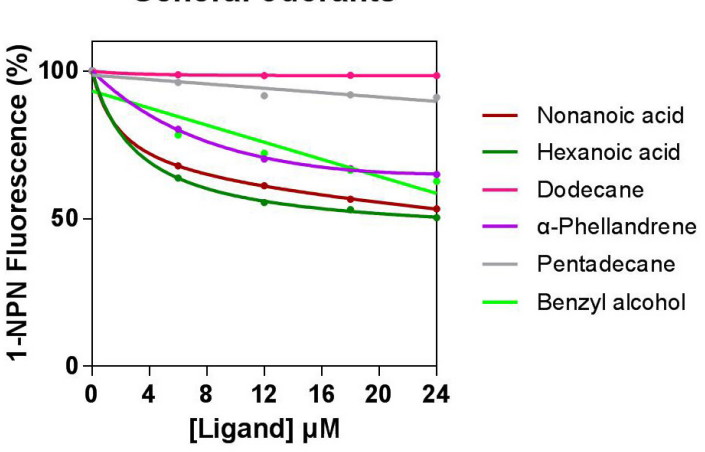

Terpenoids

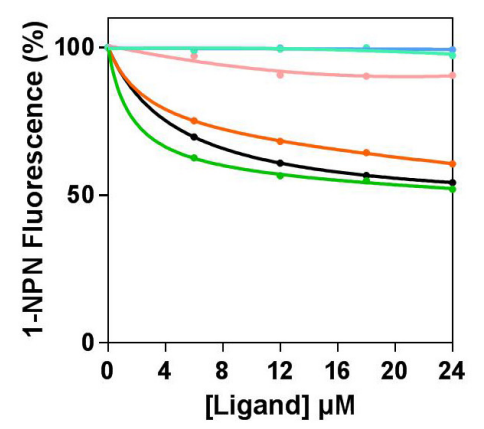

- (R)-(+)-Limonene

- Farnesol, mixture of isomers

- Farnesene, mixture of isomers

- Ocimene, mixture of isomers

- $\beta$-Caryophyllene

- a-pinene
- (R)-(+)-Limonene

- Ocimene, mixture of isomers

- $\beta$-Caryophyllene

- a-pinene

- Farnesol, mixture of isomers

- Farnesene, mixture of isomers
Green leaf volatiles

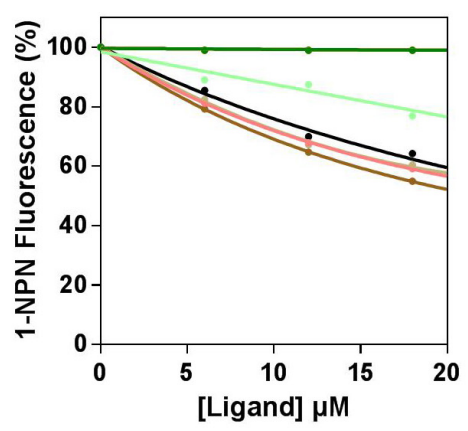

- (Z)-3-Hexen-1-ol

- (E)-3-Hexen-1-ol

- (Z)-3-Hexenyl acetate

- (E)-2-Hexenyl acetate

- (E)-2-Hexen-1-ol

- 1-Hexanol

1-Hexanal

- (E)-2-Hexenal

\section{Sex pheromones}

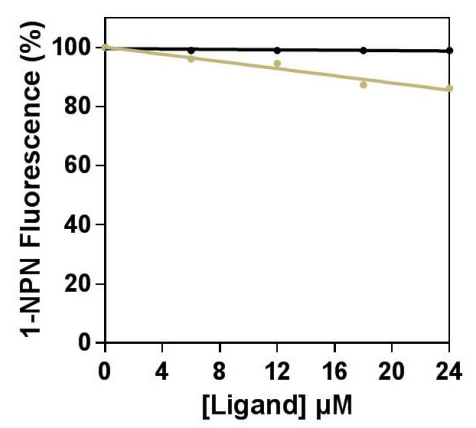

- (R)-(-)-Linalool

_ L-Leucine methyl ester

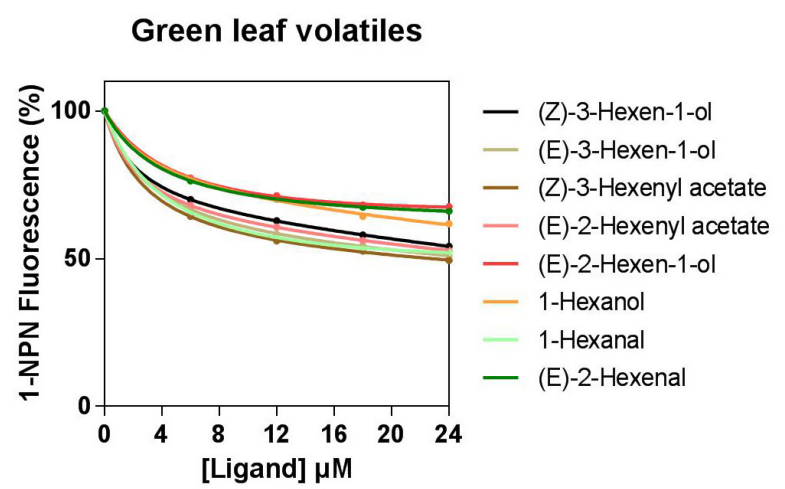

FIGURE 4 | Competitive binding curves of host-associated volatiles and sex pheromone components with HparOBPs. (A) HparOBP20; (B) HparOBP49. 
OBPs of Anomala corpulenta and the DBC were employed to construct a phylogenetic tree (Figure 1). The phylogenetic tree showed that HparOBP20 (KR733566.1) and HparOBP49
(KR733548.1) were clustered with AcorOBP7 and AcorOBP8. Analysis of expression levels indicated that compared with other HparOBPs, HparOBP20 and HparOBP49 showed higher

TABLE 1 | Fluorescence-based competitive binding affinity of host-associated volatiles and sex pheromone components to recombinant $\mathrm{HparOBPs.}$

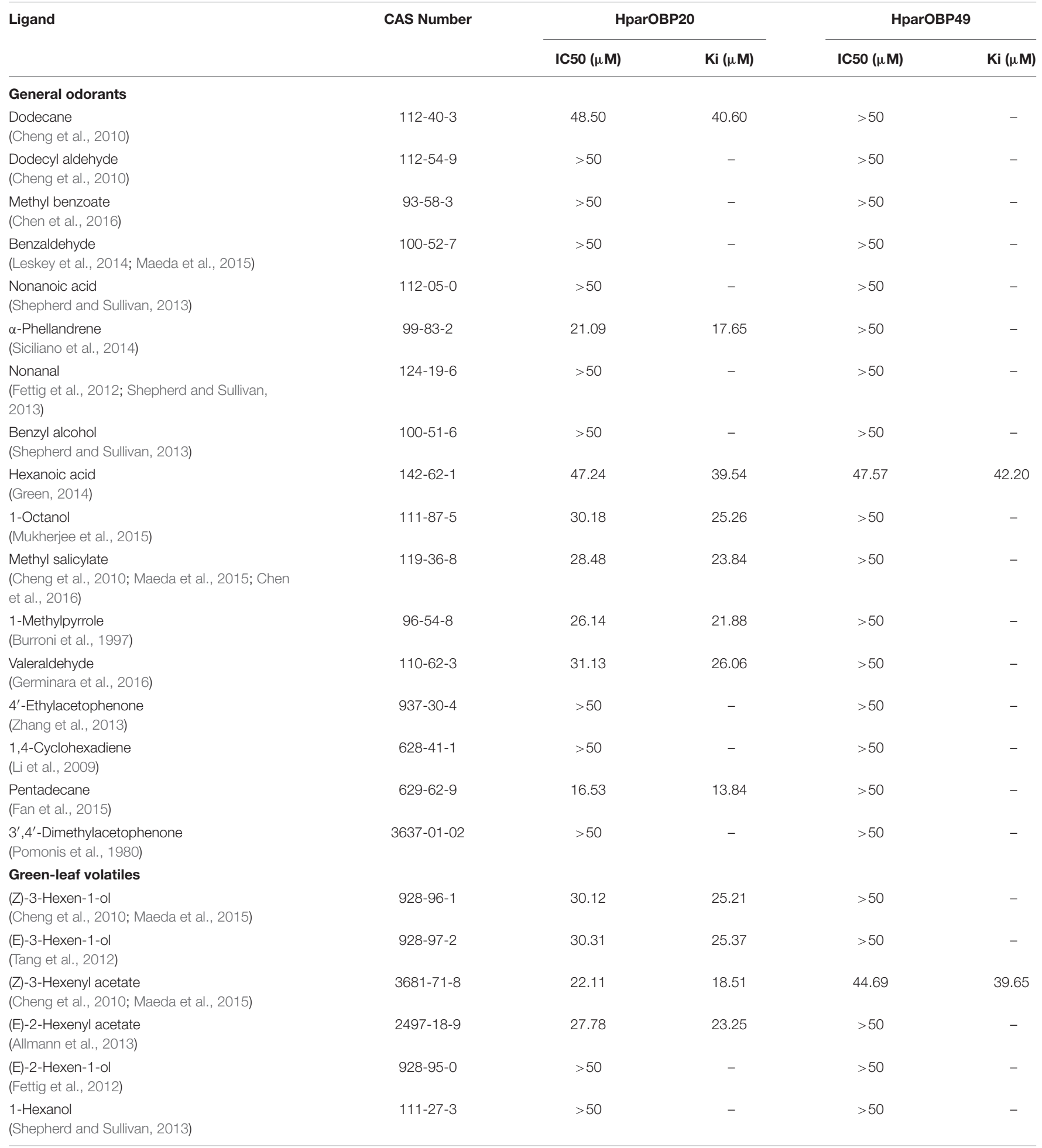


TABLE 1 | Continued

\begin{tabular}{|c|c|c|c|c|c|}
\hline \multirow[t]{2}{*}{ Ligand } & \multirow[t]{2}{*}{ CAS Number } & \multicolumn{2}{|c|}{ HparOBP20 } & \multicolumn{2}{|c|}{ HparOBP49 } \\
\hline & & IC50 ( $\mu \mathrm{M})$ & $\mathbf{K i}(\mu \mathrm{M})$ & IC50 ( $\mu \mathrm{M})$ & $\mathbf{K i}(\mu \mathrm{M})$ \\
\hline $\begin{array}{l}\text { 1-Hexanal } \\
\text { (Tang et al., 2012) }\end{array}$ & $66-25-1$ & $>50$ & - & $>50$ & - \\
\hline $\begin{array}{l}\text { (E)-2-Hexenal } \\
\text { (Fettig et al., 2012; Leskey et al., 2014; Chen } \\
\text { et al., 2016) }\end{array}$ & 6728-26-3 & $>50$ & - & $>50$ & - \\
\hline \multicolumn{6}{|l|}{ Terpenoids } \\
\hline $\begin{array}{l}\text { (R)-(+)-Limonene } \\
\text { (Cheng et al., 2010; Leskey et al., 2014; Chen } \\
\text { et al., 2016) }\end{array}$ & 5989-27-5 & 28.66 & 23.99 & $>50$ & - \\
\hline $\begin{array}{l}\text { Farnesol, mixture of isomers } \\
\text { (Cheng et al., 2010) }\end{array}$ & 4602-84-0 & $>50$ & - & $>50$ & - \\
\hline $\begin{array}{l}\text { Farnesene, mixture of isomers } \\
\text { (Cheng et al., 2010; Delaney et al., 2013) }\end{array}$ & $502-61-4$ & $>50$ & - & $>50$ & - \\
\hline $\begin{array}{l}\text { Ocimene, mixture of isomers } \\
\text { (Cheng et al., 2010) }\end{array}$ & $13877-91-3$ & $>50$ & - & $>50$ & - \\
\hline $\begin{array}{l}\beta \text {-Caryophyllene } \\
\text { (Cheng et al., 2010; Chen et al., 2016) }\end{array}$ & $87-44-5$ & $>50$ & - & $>50$ & - \\
\hline $\begin{array}{l}\alpha \text {-Pinene } \\
\text { (Cheng et al., 2010; lqbal et al., 2014) }\end{array}$ & $80-56-8$ & 26.77 & 22.41 & $>50$ & - \\
\hline \multicolumn{6}{|l|}{ Sex pheromones } \\
\hline $\begin{array}{l}\text { (R)-(-)-Linalool } \\
\text { (Leal et al., 1993) }\end{array}$ & $126-91-0$ & $>50$ & - & $>50$ & - \\
\hline $\begin{array}{l}\text { L-Leucine methyl ester } \\
\text { (Leal et al., 1993) }\end{array}$ & $7517-19-3$ & $>50$ & - & $>50$ & - \\
\hline
\end{tabular}

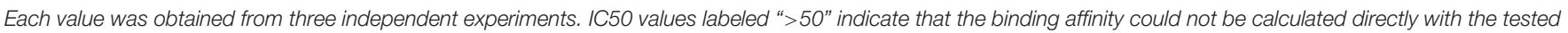
ligand concentrations. Therefore, the Ki values of these ligands are designated "-".

transcriptional activity. Therefore, HparOBP20 and HparOBP49 were selected for further analysis due to their tissue-specific expression pattern and high transcriptional activity in antennae (Ju et al., 2014).

\section{In Vitro Expression, Purification of Recombinant HparOBPs and Fluorescence Binding Assays of HparOBPs}

Recombinant HparOBPs were expressed in bacterial expression systems and purified using $\mathrm{Ni}$ ion affinity chromatography. SDS-PAGE analysis of the recombinant proteins showed that their molecular weights were $14-18 \mathrm{kDa}$, consistent with their predicted molecular masses (Figure 2).

NPN can be used as a probe in fluorescence binding assays of insect OBPs, and the binding properties of 1-NPN to OBPs have been well characterized (Sun et al., 2013; Zhuang et al., 2014; Li D.Z. et al., 2015). Therefore, 1-NPN was employed to establish saturation binding curves and Scatchard plots (Figure 3). The dissociation constants of 1-NPN with the HparOBPs, calculated using Scatchard plots, were $7.439 \pm 1.45$ (HparOBP20) and $14.67 \pm 2.96$ (HparOBP49), respectively.

A total of 33 semiochemicals, including 31 host plantassociated volatiles and two sex pheromone components, were selected for fluorescence binding assays (Figure 4 and Table 1). Among the 17 general odorants, HparOBP20 showed broad binding activity from $\mathrm{Ki}=13.84 \mu \mathrm{M}$ (pentadecane) to $40.60 \mu \mathrm{M}$ (dodecane); HparOBP49 specifically bound to hexanoic acid with a $\mathrm{Ki}$ of $42.20 \mu \mathrm{M}$. Among the eight green-leaf volatiles (GLVs), (Z)-3-hexenyl acetate showed a high binding affinity to HparOBP20 and HparOBP49, with $\mathrm{Ki}$ values of 18.51 and $39.65 \mu \mathrm{M}$, respectively. In addition, (E)-2-hexenyl acetate, (Z)-3hexen-1-ol and (E)-3-hexen-1-ol showed high binding affinities to HparOBP20, with Ki values of 23.25, 25.21, and $25.37 \mu \mathrm{M}$, respectively. Among the six terpenoids, HparOBP20 bound to $\alpha$-pinene and $(\mathrm{R})-(+)$-limonene with $\mathrm{Ki}$ values of 22.41 and $23.99 \mu \mathrm{M}$. None of the tested terpenoids could displace 1-NPN bound to HparOBP49.

\section{EAG and Olfactory Responses to Host-Associated Volatiles and Sex Pheromone Components}

Based on the results of the fluorescence binding assays, five putative ligands of the recombinant HparOBPs were selected as candidates for EAG testing in both male and female antennae (Figure 5). In males, the highest responses were observed for L-leucine methyl ester and (Z)-3-hexenyl acetate at $1 \mu \mathrm{g} / \mu \mathrm{l}$, with EAG responses of 5.68 and $4.02 \mathrm{mV}$, respectively. The highest response for females was observed for (Z)-3-hexenyl acetate at $1 \mu \mathrm{g} / \mu \mathrm{l}$, with an EAG response of $4.84 \mathrm{mV}$. The dose-dependent EAG responses to $(Z)$-3-hexenyl acetate were similar in the two sexes. Significantly different EAG responses 


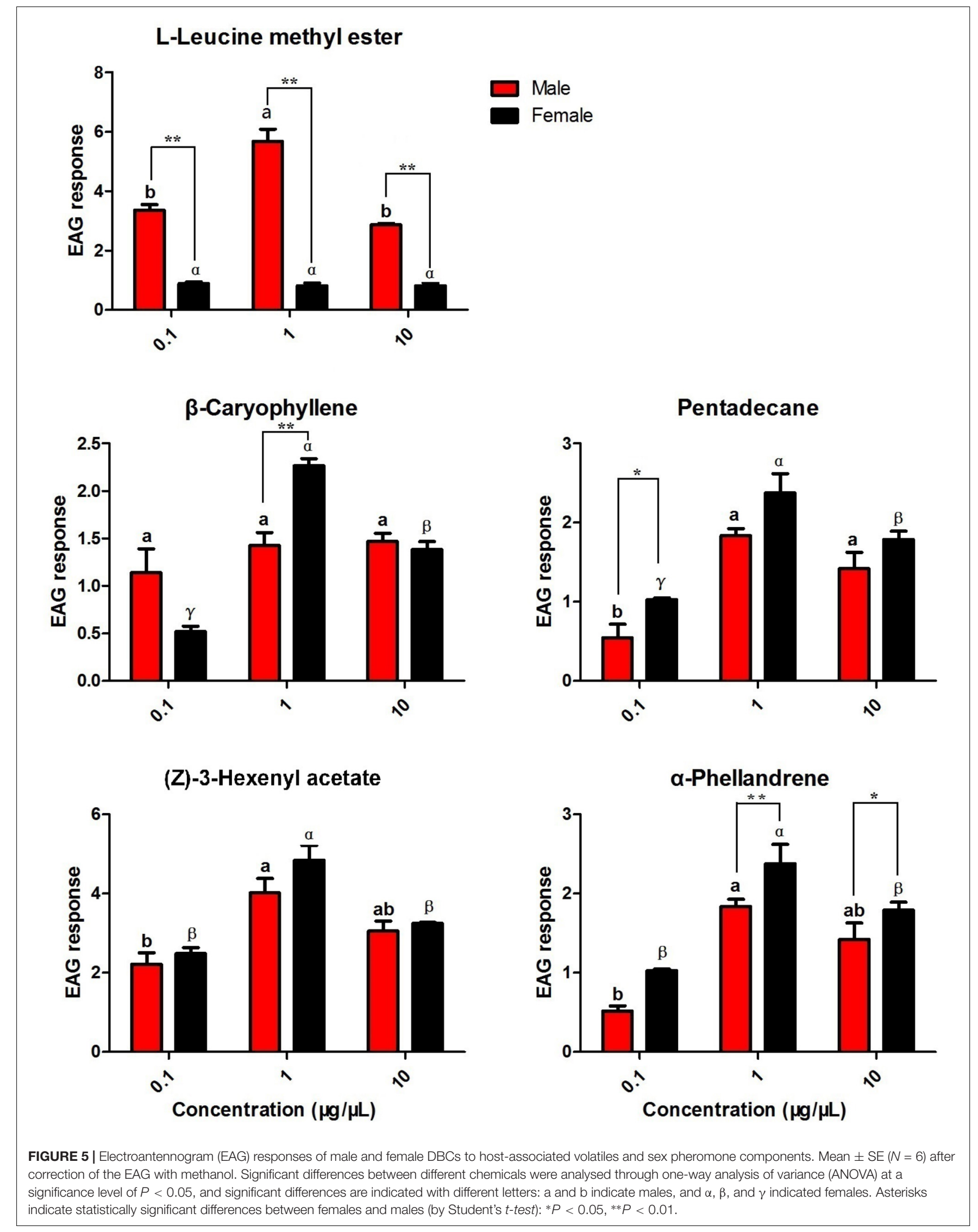




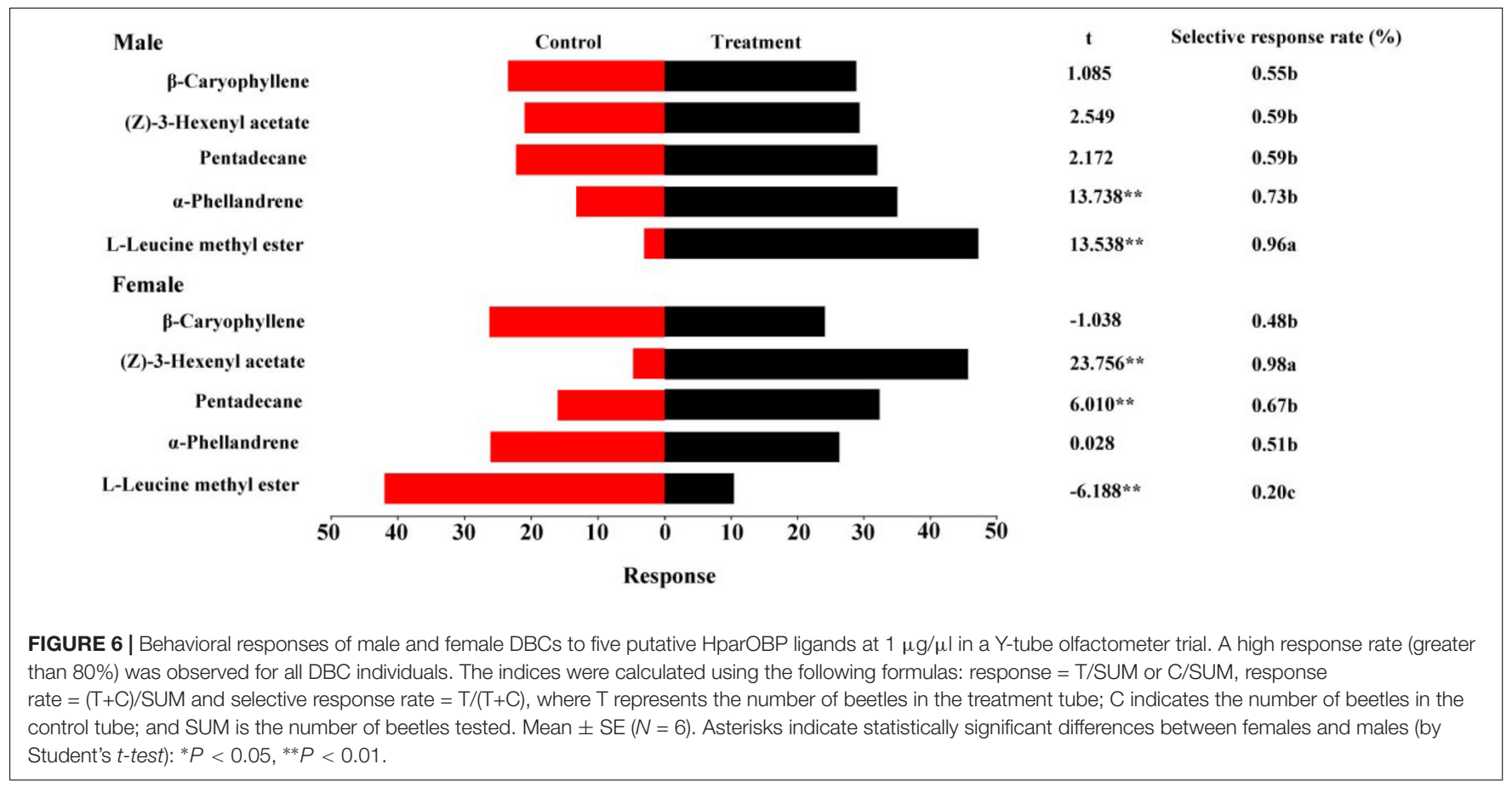

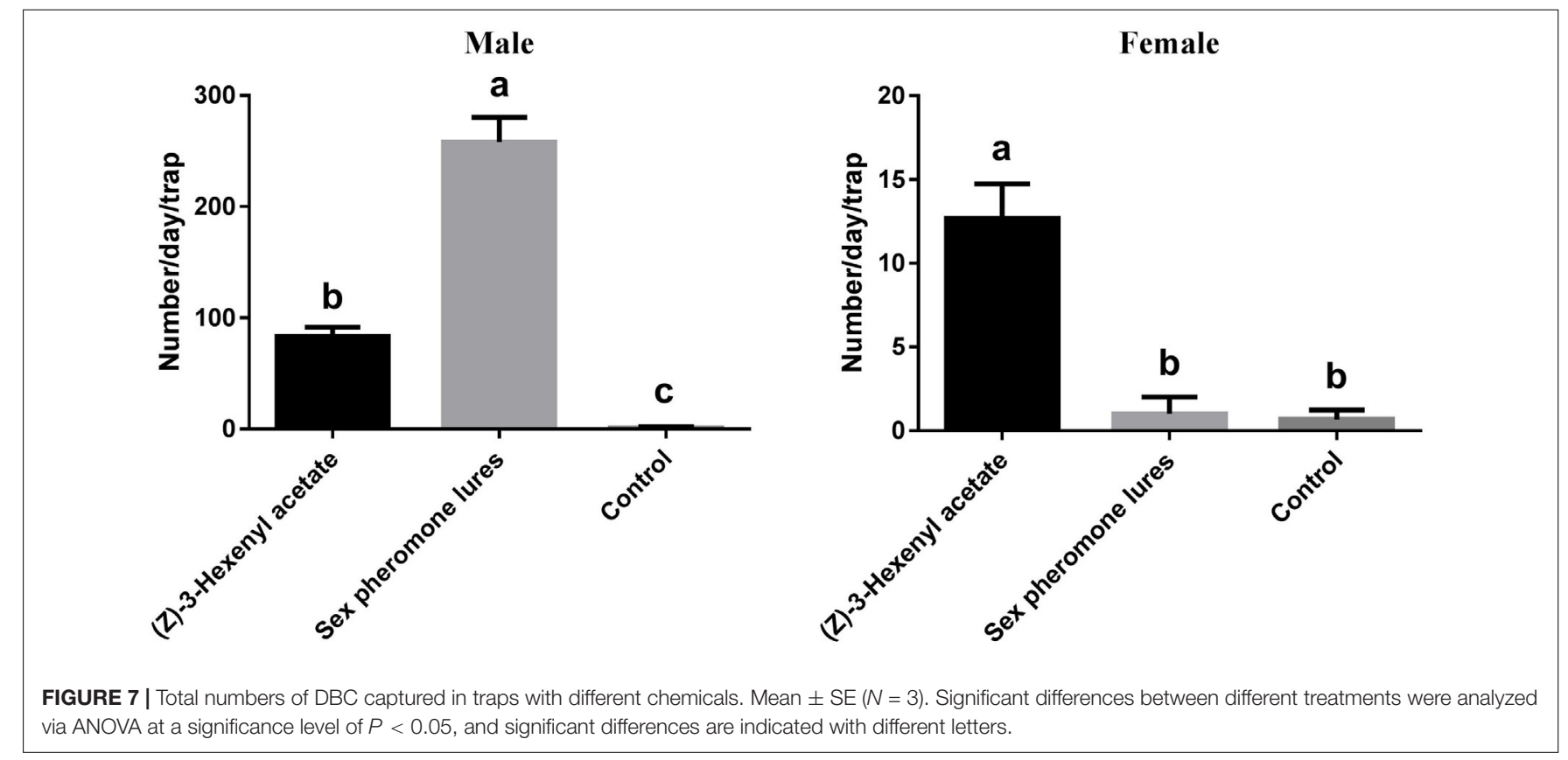

between the sexes were found for L-leucine methyl ester, with male antennae being more responsive than female antennae $(t=12.062, P<0.01$ for L-leucine methyl ester at $0.1 \mu \mathrm{g} / \mu \mathrm{l}$; $t=11.635, P<0.01$ for L-leucine methyl ester at $1 \mu \mathrm{g} / \mu \mathrm{l}$; and $t=19.231, P<0.01$ for L-leucine methyl ester at $10 \mu \mathrm{g} / \mu \mathrm{l})$. At the concentration of $1 \mu \mathrm{g} / \mu \mathrm{l}, \beta$-caryophyllene elicited a significantly higher response in female antennae than in male antennae $(t=5.350, P<0.01)$.

Figure 6 summarizes the olfactory responses of DBC adults to the tested volatiles at $1 \mu \mathrm{g} / \mu \mathrm{l}$. A good response rate
(>80\%) suggested that the tests were valid. Similar to the EAG responses, the highest selective response rate of females to (Z)-3-hexenyl acetate was $98 \%$. A significantly higher selective response rate in males (96\%) than in females was observed for L-leucine methyl ester. Significant differences in behavioral responses were observed between the controls and treatments for $\alpha$-phellandrene and L-leucine methyl ester, with the treatment being more attractive than the control $(t=13.738, P<0.01$ for $\alpha$-phellandrene; $t=13.538, P<0.01$ for L-leucine methyl ester). Females exhibited upwind movement into the volatiles 
containing pentadecane and (Z)-3-hexenyl acetate $(t=6.010$, $P<0.01$ for pentadecane, $t=23.756, P<0.01$ for $(Z)$-3-hexenyl acetate). L-Leucine methyl ester, an established sex pheromone component, attracted few female adults $(t=-6.188, P<0.01)$.

\section{Field Evaluation}

Based on the EAG and olfactory responses, L-leucine methyl ester and (Z)-3-hexenyl acetate were selected for field evaluation (Figure 7). The results showed that all of the tested lures attracted more males than females. The sex pheromone resulted in significantly higher male catches than $(Z)$-3-hexenyl acetate $\left(F_{2,6}=272.1, P<0.0001\right)$. For males, $(Z)$-3-hexenyl acetate yielded $83 \pm 4.933 \mathrm{DBCs}$, and the sex pheromone yielded $258 \pm 12.860$. The average number of females per trap per day was $13 \pm 1.202$ using $(Z)$-3-hexenyl acetate $\left(F_{2,6}=74.18, P<0.0001\right)$.

\section{DISCUSSION}

In this study, we focused on OBPs, which are relatively accessible targets for research, because they are small, soluble, stable and relatively easy to manipulate and modify (Brito et al., 2016; Leal, 2017; Zhu et al., 2017). A. corpulenta Motschulsky (Coleoptera: Scarabaeidae: Rutelinae) and DBC larvae, which are the main pests in many crop fields, exhibit overlapping active times, and adults of these species also overlap on some host plant species. Therefore, these pests may exhibit similar olfactory proteins in their olfactory systems, which could be the functional proteins interacting with plant volatiles. In A. corpulenta, AcroOBP7 and AcroOBP8 display antenna-specific expression ( $\mathrm{Li} \mathrm{X}$. et al., 2015), and HparOBP20 and HparOBP49 exhibit antenna-specific expression in $H$. parallela (Ju et al., 2014). We have revised the nomenclature system of the Holotrichia parallela OBP genes in this paper. The OBP2 gene from the previous study (Ju et al., 2014) has been renamed HparOBP49. We hypothesize that these proteins are responsible for chemical communication, and the phylogenetic tree of $A$. corpulenta and $H$. parallela showed that HparOBP20 and HparOBP49 clustered with AcorOBP7 and AcorOBP8. Furthermore, an analysis of expression levels indicated that HparOBP20 and HparOBP49 showed higher transcriptional activity than that of other HparOBPs. Therefore, HparOBP20 and HparOBP49 were selected for further study. Their binding specificity may pave the way for the identification of active host plant volatiles.

To confirm the functions suggested by the phylogenetic tree, along with the tissue expression profiles and quantification analysis, the binding affinity of the two HparOBPs to 33 volatiles was determined using fluorescent binding assays. All the volatile compounds tested in this study were isolated from DBC host plants and may be biologically significant for the DBC. We found that HparOBP20 showed a broad spectrum of binding activity, and HparOBP49 specifically bound to general odorants and GLVs. Overall, HparOBP20 exhibited a high binding affinity to three volatiles $(\mathrm{Ki}<20 \mu \mathrm{M})$ : pentadecane, (Z)-3-Hexenyl acetate and $\alpha$-phellandrene. However, all the volatiles tested in this study showed a relatively weak binding affinity $(\mathrm{Ki}>20 \mu \mathrm{M})$ to HparOBP49. Compensation effects may exist between HparOBP20 and HparOBP49, as observed for Cnaphalocrocis medinalis OBP2 and OBP3 (Sun et al., 2016), and Chrysopa pallens OBP3, -6 and -10 (Li et al., 2017).

Among the three compounds that displayed a high binding affinity $(\mathrm{Ki}<20 \mu \mathrm{M})$ to HparOBP20, (Z)-3-hexenyl acetate showed a higher affinity to both HparOBP20 and HparOBP49. (Z)-3-Hexenyl acetate is a GLV metabolized from one of the most abundant GLVs, (Z)-3-hexenal (Deng et al., 2004; Matsui, 2006; D’Auria et al., 2007; Allmann et al., 2013). (Z)-3-Hexenyl acetate is a common plant volatile released in large amounts after damage and plays important roles in insect-plant interactions (Arimura et al., 2008; Mumm and Dicke, 2010; Szendrei et al., 2011; von Arx et al., 2012). For example, a mixture of plant volatiles including (Z)-3-hexenyl acetate attracts the Colorado potato beetle, Leptinotarsa decemlineata Say (Visser, 1986), and the scarab beetle Anomala octiescostata Burmeister (Leal et al., 1994). Here, we tested the behavioral response and field attraction of the DBC to (Z)-3-hexenyl acetate, and a clear behavioral influence was observed in the EAG, Y-tube and field evaluations. The results were consistent with those of previous studies. Furthermore, (Z)-3-hexenyl acetate has been confirmed to activate olfactory sensory neurons (OSNs) expressing different sets of odorant receptor types on Manduca sexta female antennae (Allmann et al., 2013) and to enhance the responses of some insect species to sex pheromones (Deng et al., 2004; Varela et al., 2011; Ju et al., 2017). In the field, (Z)-3-hexenyl acetate mixed with sex pheromone in a 1:1 ratio increased the number of trapcaught females by 6- to 7-fold and the number of males by 20-30\% compared with traps baited with sex pheromone alone (Reddy and Guerrero, 2000). Therefore, the synergistic effect between (Z)-3-hexenyl acetate and the sex pheromone requires further study. However, it is worth noting that, while (E)-2hexenyl acetate displayed a lower binding affinity $(\mathrm{Ki}=23.25)$ to HparOBP20, when it was employed in a trap along with the DBC sex pheromone, many DBCs were caught (Ju et al., 2017).

The general odorants pentadecane and $\alpha$-phellandrene showed a higher binding affinity $(\mathrm{Ki}<20 \mu \mathrm{M})$ to HparOBP20 and exerted a clear influence on behavior in the EAG and Y-tube assays but exhibited a low attractant ability in traps. Fluorescence binding assays often provide candidate compounds, but not all of the screened compounds exhibit biological activity in insects (Yi et al., 2018). AfunOBP1 from Anopheles funestus binds to 1-octen-3-ol, but when 1-octen-3-ol was used in a trap, only a few mosquito species were caught (Xu et al., 2010). However, pentadecane has been reported to bind to a Locusta migratoria OBP (Jiang et al., 2009), and the molecular docking results for $\alpha$-phellandrene showed that it could tightly bind to the Adelphocoris lineolatus OBP6 pocket (Sun et al., 2017b). In the future, we may focus more research effort on these two odorants to obtain a greater number of DBC attractants.

\section{AUTHOR CONTRIBUTIONS}

QJ and XL analyzed and interpreted the data and performed the molecular examination. X-QG and LD performed the EAG and olfactory response examination. 
C-RS performed the field examination. M-JQ was a major contributor in writing the manuscript. All authors read and approved the final manuscript.

\section{FUNDING}

This study was funded by research grants from the National Key R\&D Program of China (2017YFD0200400), China Agriculture

\section{REFERENCES}

Aartsma, Y., Bianchi, F. J. J. A., van der Werf, W., Poelman, E. H., and Dicke, M. (2017). Herbivore-induced plant volatiles and tritrophic interactions across spatial scales. New Phytol. 216, 1054-1063. doi: 10.1111/nph.14475

Allmann, S., Spathe, A., Bisch-Knaden, S., Kallenbach, M., Reinecke, A., Sachse, S., et al. (2013). Feeding-induced rearrangement of green leaf volatiles reduces moth oviposition. eLife 2:e00421.

Arimura, G. I., Kopke, S., Kunert, M., Volpe, V., David, A., Brand, P., et al. (2008). Effects of feeding Spodoptera littoralis on lima bean leaves: IV. Diurnal and nocturnal damage differentially initiate plant volatile emission. Plant Physiol. 146, 965-973. doi: 10.1104/pp.107.111088

Brito, N. F., Moreira, M. F., and Melo, A. C. A. (2016). A look inside odorantbinding proteins in insect chemoreception. J. Insect Physiol. 95, 51-65. doi: 10.1016/j.jinsphys.2016.09.008

Burroni, L. V., Grosso, N. R., and Guzman, C. A. (1997). Principal volatile components of raw, roasted, and fried Argentinean peanut flavors. J. Agric. Food Chem. 45, 3190-3192. doi: 10.1021/jf9700034

Chen, Y., Ulyshen, M. D., and Poland, T. M. (2016). Abundance of volatile organic compounds in white ash phloem and emerald ash borer larval frass does not attract Tetrastichus planipennisi in a Y-tube olfactometer. Insect Sci. 23, 712-719. doi: 10.1111/1744-7917.12227

Cheng, B., Fu, X. X., Han, Q., Zhang, B. M., Zhang, D. M., Li, X. P., et al. (2010). Effects of herbivore-induced Ulmus pumila volatiles on the host selection process of Ambrostoma quadriimpressum. Sci. Silvae Sin. 46, 76-82.

Collignon, R. M., Swift, I. P., Zou, Y. F., McElfresh, J. S., Hanks, L. M., and Millar, J. G. (2016). The influence of host plant volatiles on the attraction of longhorn beetles to pheromones. J. Chem. Ecol. 42, 215-229. doi: 10.1007/s10886-0160679-x

D’Auria, J. C., Pichersky, E., Schaub, A., Hansel, A., and Gershenzon, J. (2007). Characterization of a BAHD acyltransferase responsible for producing the green leaf volatile (Z)-3-hexen-1-yl acetate in Arabidopsis thaliana. Plant J. 49, 194-207. doi: 10.1111/j.1365-313X.2006.02946.x

Delaney, K. J., Wawrzyniak, M., Lemanczyk, G., Wrzesinska, D., and Piesik, D. (2013). Synthetic cis-jasmone exposure induces wheat and barley volatiles that repel the pest cereal leaf beetle, Oulema melanopus L. J. Chem. Ecol. 39, 620-629. doi: 10.1007/s10886-013-0281-4

Deng, J. Y., Wei, H. Y., Huang, Y. P., and Du, J. W. (2004). Enhancement of attraction to sex pheromones of Spodoptera exigua by volatile compounds produced by host plants. J. Chem. Ecol. 30, 2037-2045. doi: 10.1023/B:JOEC. 0000045593.62422 .73

Deng, S., Yin, J., Zhong, T., Cao, Y., and Li, K. (2012). Function and immunocytochemical localization of two novel odorant-binding proteins in olfactory sensilla of the scarab beetle Holotrichia oblita Faldermann (Coleoptera: Scarabaeidae). Chem. Senses 37, 141-150. doi: 10.1093/chemse/ bjr084

Fan, L., Niu, H., Zhang, J., Liu, J., Yang, M., and Zong, S. (2015). Extraction and identification of aggregation pheromone components of Scolytus schevyrewi Semenov (Coleoptera Scolytidae) and trapping test. Acta Ecol. Sin. 35, 892-899.

Fettig, C. J., McKelvey, S. R., Dabney, C. P., and Huber, D. P. W. (2012). Responses of Dendroctonus brevicomis (Coleoptera: Curculionidae) in behavioral assays: implications to development of a semiochemical-based tool for tree protection. J. Econ. Entomol. 105, 149-160. doi: 10.1603/EC11121

Galindo, K., and Smith, D. P. (2001). A large family of divergent drosophila odorant-binding proteins expressed in gustatory and olfactory sensilla. Genetics 159, 1059-1072.
Research System (CARS-14), and the Youth Fund of Shandong Academy of Agriculture Sciences (2016YQN15).

\section{SUPPLEMENTARY MATERIAL}

The Supplementary Material for this article can be found online at: https://www.frontiersin.org/articles/10.3389/fphys. 2018.00769/full\#supplementary-material

Germinara, G. S., De Cristofaro, A., and Rotundo, G. (2016). Electrophysiological and behavioral responses of Theocolax elegans (Westwood) (Hymenoptera: Pteromalidae) to cereal grain volatiles. Biomed Res. Int. 2016:5460819. doi: $10.1155 / 2016 / 5460819$

Green, P. W. C. (2014). Volatile compounds from Liposcelis bostrychophila (Psocoptera: Liposcelididae) and their environment and their effects on settling behaviour. Biochem. Syst. Ecol. 57, 81-89. doi: 10.1016/j.bse.2014.07.025

Hanks, L. M., and Millar, J. G. (2013). Field bioassays of cerambycid pheromones reveal widespread parsimony of pheromone structures, enhancement by host plant volatiles, and antagonism by components from heterospecifics. Chemoecology 23, 21-44. doi: 10.1007/s00049-012-0116-8

Hanks, L. M., Millar, J. G., Mongold-Diers, J. A., Wong, J. C. H., Meier, L. R., Reagel, P. F., et al. (2012). Using blends of cerambycid beetle pheromones and host plant volatiles to simultaneously attract a diversity of cerambycid species. Can. J. Forest Res. 42, 1050-1059. doi: 10.1093/jee/tox373

Horst, R., Damberger, F., Luginbuhl, P., Guntert, P., Peng, G., Nikonova, L., et al. (2001). NMR structure reveals intramolecular regulation mechanism for pheromone binding and release. Proc. Natl. Acad. Sci. U.S.A. 98, 14374-14379. doi: 10.1073/pnas.251532998

Iqbal, M. A., Kim, K. H., and Ahn, J. H. (2014). Monoterpenes released from fruit, plant, and vegetable systems. Sensors 14, 18286-18301. doi: 10.3390/s141018286

Isberg, E., Bray, D. P., Hillbur, Y., and Ignell, R. (2017). Evaluation of host-derived volatiles for trapping Culicoides biting midges (Diptera: Ceratopogonidae). J. Chem. Ecol. 43, 662-669. doi: 10.1007/s10886-017-0860-x

Jayanthi, K. P., Kempraj, V., Aurade, R. M., Roy, T. K., Shivashankara, K. S., and Verghese, A. (2014). Computational reverse chemical ecology: virtual screening and predicting behaviorally active semiochemicals for Bactrocera dorsalis. BMC Genomics 15:209. doi: 10.1186/1471-2164-15-209

Jiang, Q. Y., Wang, W. X., Zhang, Z., and Zhang, L. (2009). Binding specificity of locust odorant binding protein and its key binding site for initial recognition of alcohols. Insect Biochem. Mol. Biol. 39, 440-447. doi: 10.1016/j.ibmb.2009.04. 004

Ju, Q., Guo, X.-Q., Li, X., Jiang, X.-J., Jiang, X.-G., Ni, W.-L., et al. (2017). Plant volatiles increase sex pheromone attraction of Holotrichia parallela (Coleoptera: Scarabaeoidea). J. Chem. Ecol. 43, 236-242. doi: 10.1007/s10886-017-0823-2

Ju, Q., Li, X., Jiang, X. J., Qu, M. J., Guo, X. Q., Han, Z. J., et al. (2014). Transcriptome and tissue-specific expression analysis of OBP and CSP genes in the dark black chafer. Arch. Insect Biochem. Physiol. 87, 177-200. doi: 10.1002/ arch. 21188

Ju, Q., Qu, M. J., Wang, Y., Jiang, X. J., Li, X., Dong, S. L., et al. (2012). Molecular and biochemical characterization of two odorant-binding proteins from dark black chafer, Holotrichia parallela. Genome 55, 537-546. doi: 10.1139/g2012042

Jung, C. R., Jung, J. K., and Kim, Y. (2013). Effects of different sex pheromone compositions and host plants on the mating behavior of two Grapholita species. J. Asia Pac. Entomol. 16, 507-512. doi: 10.1016/j.aspen.2013.08.004

Katoh, K., Asimenos, G., and Toh, H. (2009). Multiple alignment of DNA sequences with MAFFT. Methods Mol. Biol. 537, 39-64. doi: 10.1007/978-159745-251-9_3

Klein, U. (1987). Sensillum-lymph proteins from antennal olfactory hairs of the moth antheraea-polyphemus (saturniidae). Insect Biochem. 17, 1193-1204. doi: 10.1016/0020-1790(87)90093-X

Koczor, S., Vuts, J., and Toth, M. (2012). Attraction of Lygus rugulipennis and Adelphocoris lineolatus to synthetic floral odour compounds in field experiments in Hungary. J. Pest Sci. 85, 239-245. doi: 10.1007/s10340-0120422-5 
Lam-Tung, N., Schmidt, H. A., von Haeseler, A., and Bui Quang, M. (2015). IQ-TREE: a fast and effective stochastic algorithm for estimating maximumlikelihood phylogenies. Mol. Biol. Evol. 32, 268-274. doi: 10.1093/molbev/ msu300

Laughlin, J. D., Ha, T. S., Jones, D. N., and Smith, D. P. (2008). Activation of pheromone-sensitive neurons is mediated by conformational activation of pheromone-binding protein. Cell 133, 1255-1265. doi: 10.1016/j.cell.2008.04. 046

Leal, W. S. (2013). Odorant reception in insects: roles of receptors, binding proteins, and degrading enzymes. Annu. Rev. Entomol. 58, 373-391. doi: 10.1146/annurev-ento-120811-153635

Leal, W. S. (2017). Reverse chemical ecology at the service of conservation biology. Proc. Natl. Acad. Sci. U.S.A. 114, 12094-12096. doi: 10.1073/pnas.1717375114

Leal, W. S., Chen, A. M., and Erickson, M. L. (2005). Selective and pH-dependent binding of a moth pheromone to a pheromone-binding protein. J. Chem. Ecol. 31, 2493-2499. doi: 10.1007/s10886-005-7458-4

Leal, W. S., Ono, M., Hasegawa, M., and Sawada, M. (1994). Kairomone from dandelion, Taraxacum officinale, attractant for scarab beetle Anomala octiescostata. J. Chem. Ecol. 20, 1697-1704. doi: 10.1007/BF02059891

Leal, W. S., Sawada, M., Matsuyama, S., Kuwahara, Y., and Hasegawa, M. (1993). Unusual periodicity of sex-pheromone production in the large black chafer Holotrichia parallela. J. Chem. Ecol. 19, 1381-1391. doi: 10.1007/BF00984883

Lee, J. C., Hamud, S. M., Negron, J. F., Witcosky, J. J., and Seybold, S. J. (2010). Semiochemical-mediated flight strategies of two invasive elm bark beetles: a potential factor in competitive displacement. Environ. Entomol. 39, 642-652. doi: 10.1603/EN09327

Leskey, T. C., Hock, V., Chouinard, G., Cormier, D., Leahy, K., Cooley, D., et al. (2014). Evaluating electrophysiological and behavioral responses to volatiles for improvement of odor-baited trap tree management of Conotrachelus nenuphar (Coleoptera: Curculionidae). Environ. Entomol. 43, 753-761. doi: 10.1603/ EN13230

Li, D. Z., Yu, G. Q., Yi, S. C., Zhang, Y., Kong, D. X., and Wang, M. Q. (2015). Structure-based analysis of the ligand-binding mechanism for DhelOBP21, a C-minus odorant binding protein, from Dastarcus helophoroides (Fairmaire; Coleoptera: Bothrideridae). Int. J. Biol. Sci. 11, 1281-1295. doi: 10.7150/ijbs. 12528

Li, G., Chen, X., Li, B., Zhang, G., Li, Y., and Wu, J. (2016). Binding properties of general odorant binding proteins from the oriental fruit moth, Grapholita molesta (Busck) (Lepidoptera: Tortricidae). PLoS One 11:e0155096. doi: 10.1371/journal.pone.0155096

Li, R., Chen, W. C., Wang, W. P., Tian, W. Y., and Zhang, X. G. (2009). Analysis of the essential oil of magnolia and its effect on antioxidant enzyme activity, sCD40L and phosphorylate-activate Akt protein levels in gastric cancer mice. Med. Chem. Res. 19, 1203-1209. doi: 10.1007/s00044-009-9263-z

Li, X., Ju, Q., Jie, W., Li, F., Jiang, X., Hu, J., et al. (2015). Chemosensory gene families in adult antennae of Anomala corpulenta Motschulsky (Coleoptera: Scarabaeidae: Rutelinae). PLoS One 10:e0121504. doi: 10.1371/journal.pone. 0121504

Li, Z. Q., Zhang, S., Cai, X. M., Luo, J. Y., Dong, S. L., Cui, J. J., et al. (2017). Three odorant binding proteins may regulate the behavioural response of Chrysopa pallens to plant volatiles and the aphid alarm pheromone (E) $\beta$-farnesene. Insect Mol. Biol. 26, 255-265. doi: 10.1111/imb.12295

Liu, N. Y., Yang, F., Yang, K., He, P., Niu, X. H., Xu, W., et al. (2015). Two subclasses of odorant-binding proteins in Spodoptera exigua display structural conservation and functional divergence. Insect Mol. Biol. 24, 167-182. doi: $10.1111 / \mathrm{imb} .12143$

Liu, N. Y., Zhu, J.-Y., Zhang, T., and Dong, S.-L. (2017). Characterization of two odorant binding proteins in Spodoptera exigua reveals functional conservation and difference. Comp. Biochem. Physiol. A Mol. Integr. Physiol. 213, 20-27. doi: 10.1016/j.cbpa.2017.08.002

Maeda, T., Kishimoto, H., Wright, L. C., and James, D. G. (2015). Mixture of synthetic herbivore-induced plant volatiles attracts more Stethorus punctum picipes (Casey) (Coleoptera: Coccinellidae) than a single volatile. J. Insect. Behav. 28, 126-137. doi: 10.1007/s10905-015-9489-1

Mao, Y., Xu, X., Xu, W., Ishida, Y., Leal, W. S., Ames, J. B., et al. (2010). Crystal and solution structures of an odorant-binding protein from the southern house mosquito complexed with an oviposition pheromone. Proc. Natl. Acad. Sci. U.S.A. 107, 19102-19107. doi: 10.1073/pnas.1012274107
Matsui, K. (2006). Green leaf volatiles: hydroperoxide lyase pathway of oxylipin metabolism. Curr. Opin. Plant Biol. 9, 274-280. doi: 10.1016/j.pbi.2006.03.002

Matsuo, T., Sugaya, S., Yasukawa, J., Aigaki, T., and Fuyama, Y. (2007). Odorantbinding proteins OBP57d and OBP57e affect taste perception and host-plant preference in Drosophila sechellia. PLoS Biol. 5:985-996. doi: 10.1371/journal. pbio. 0050118

Mukherjee, A., Sarkar, N., and Barik, A. (2015). Momordica cochinchinensis (Cucurbitaceae) leaf volatiles: semiochemicals for host location by the insect pest, Aulacophora foveicollis (Coleoptera: Chrysomelidae). Chemoecology 25, 93-104. doi: 10.1007/s00049-014-0179-9

Mumm, R., and Dicke, M. (2010). Variation in natural plant products and the attraction of bodyguards involved in indirect plant defense. Can. J. Zool. 88, 628-667. doi: 10.1139/Z10-032

Pelosi, P., Iovinella, I., Felicioli, A., and Dani, F. R. (2014). Soluble proteins of chemical communication: an overview across arthropods. Front. Physiol. 5:320. doi: 10.3389/fphys.2014.00320

Pertea, G., Huang, X. Q., Liang, F., Antonescu, V., Sultana, R., Karamycheva, S., et al. (2003). TIGR Gene Indices clustering tools (TGICL): a software system for fast clustering of large EST datasets. Bioinformatics 19, 651-652. doi: 10.1093/ bioinformatics/btg034

Pomonis, J. G., Flint, H. M., and Smith, R. L. (1980). Analysis of volatiles from host and nonhost plants of the pink-bollworm (lepidoptera, gelecuiidae). J. Econ. Entomol. 73, 783-786. doi: 10.1093/jee/73.6.783

Qiao, H., Tuccori, E., He, X., Gazzano, A., Field, L., Zhou, J.-J., et al. (2009). Discrimination of alarm pheromone (E)- $\beta$-farnesene by aphid odorant-binding proteins. Insect Biochem. Mol. Biol. 39, 414-419. doi: 10.1016/j.ibmb.2009.03. 004

Reddy, G. V. P., and Guerrero, A. (2000). Behavioral responses of the diamondback moth, plutella xylostella, to green leaf volatiles of Brassica oleracea subsp capitata. J. Agric. Food Chem. 48, 6025-6029. doi: 10.1021/jf0008689

Reddy, G. V. P., and Guerrero, A. (2004). Interactions of insect pheromones and plant semiochemicals. Trends Plant Sci. 9, 253-261. doi: 10.1016/j.tplants.2004. 03.009

Rice, P., Longden, I., and Bleasby, A. (2000). EMBOSS: the European molecular biology open software suite. Trends Genet. 16, 276-277. doi: 10.1016/S01689525(00)02024-2

Said, I., Renou, M., Morin, J. P., Ferreira, J. M. S., and Rochat, D. (2005). Interactions between acetoin, a plant volatile, and pheromone in Rhynchophorus palmarum: behavioral and olfactory neuron responses. J. Chem. Ecol. 31, 1789-1805. doi: 10.1007/s10886-005-5927-4

Sandler, B. H., Nikonova, L., Leal, W. S., and Clardy, J. (2000). Sexual attraction in the silkworm moth: structure of the pheromone-binding-protein-bombykol complex. Chem. Biol. 7, 143-151. doi: 10.1016/S1074-5521(00)00078-8

Shan, Y., Shu, C., Crickmore, N., Liu, C., Xiang, W., Song, F., et al. (2014). Cultivable gut bacteria of scarabs (Coleoptera: Scarabaeidae) inhibit Bacillus thuringiensis multiplication. Environ. Entomol. 43, 612-616. doi: 10.1603/ EN14028

Shepherd, W. P., and Sullivan, B. T. (2013). Southern pine beetle, Dendroctonus frontalis, antennal and behavioral responses to nonhost leaf and bark volatiles. J. Chem. Ecol. 39, 481-493. doi: 10.1007/s10886-013-0265-4

Shi, Y., Li, D. W., Chen, Y., and He, X. Y. (2011). Emissions of isoprenoid from major planting tree species in Shenyang. Adv. Mater. Res. 18, 1041-1045. doi: 10.4028/www.scientific.net/AMR.183-185.1041

Siciliano, P., He, X. L., Woodcock, C., Pickett, J. A., Field, L. M., Birkett, M. A., et al. (2014). Identification of pheromone components and their binding affinity to the odorant binding protein CcapOBP83a-2 of the Mediterranean fruit fly, Ceratitis capitata. Insect Biochem. Mol. Biol. 48, 51-62. doi: 10.1016/j.ibmb.2014. 02.005

Sun, L., Gu, S.-H., Xiao, H.-J., Zhou, J.-J., Guo, Y.-Y., Liu, Z.-W., et al. (2013). The preferential binding of a sensory organ specific odorant binding protein of the alfalfa plant bug Adelphocoris lineolatus AlinOBP10 to biologically active host plant volatiles. J. Chem. Ecol. 39, 1221-1231. doi: 10.1007/s10886-013-0333-9

Sun, L., Wang, Q., Wang, Q., Dong, K., Xiao, Y., and Zhang, Y.-J. (2017a). Identification and characterization of odorant binding proteins in the forelegs of Adelphocoris lineolatus (Goeze). Front. Physiol. 8:735. doi: 10.3389/fphys. 2017.00735

Sun, L., Wang, Q., Yang, S., Wang, Q., Zhang, Z., Khashaveh, A., et al. (2017b). Functional analysis of female-biased odorant binding protein 6 for volatile and 
nonvolatile host compounds in Adelphocoris lineolatus (Goeze). Insect Mol. Biol. 26, 601-615. doi: 10.1111/imb.12322

Sun, X., Zeng, F. F., Yan, M. J., Zhang, A., Lu, Z. X., and Wang, M. Q. (2016). Interactions of two odorant-binding proteins influence insect chemoreception. Insect Mol. Biol. 25, 712-723. doi: 10.1111/imb.12256

Sun, Y. F., De Biasio, F., Qiao, H. L., Iovinella, I., Yang, S. X., Ling, Y., et al. (2012). Two odorant-binding proteins mediate the behavioural response of aphids to the alarm pheromone (E)-beta-arnesene and structural analogues. PLoS One 7:e32759. doi: 10.1371/journal.pone.0032759

Swarup, S., Williams, T. I., and Anholt, R. R. H. (2011). Functional dissection of odorant binding protein genes in Drosophila melanogaster. Genes Brain Behav. 10, 648-657. doi: 10.1111/j.1601-183X.2011.00704.x

Szendrei, Z., Averill, A., Alborn, H., and Rodriguez-Saona, C. (2011). Identification and field evaluation of attractants for the cranberry weevil, Anthonomus musculus say. J. Chem. Ecol. 37, 387-397. doi: 10.1007/s10886-011-9 938-z

Tang, R., Zhang, J. P., and Zhang, Z. N. (2012). Electrophysiological and behavioral responses of male fall webworm moths (Hyphantria cunea) to Herbivoryinduced mulberry (Morus alba) leaf volatiles. PLoS One 7:e49256. doi: 10.1371/ journal.pone.0049256

Varela, N., Avilla, J., Anton, S., and Gemeno, C. (2011). Synergism of pheromone and host-plant volatile blends in the attraction of Grapholita molesta males. Entomol. Exp. Appl. 141, 114-122. doi: 10.1111/j.1570-7458.2011.01 171.x

Visser, J. H. (1986). Host odor perception in phytophagous insects. Annu. Rev. Entomol. 31, 121-144. doi: 10.1098/rspb.2016.2101

Vogt, R. G., and Riddiford, L. M. (1981). Pheromone binding and inactivation by moth antennae. Nature 293, 161-163. doi: 10.1038/293161a0

Vogt, R. G., Riddiford, L. M., and Prestwich, G. D. (1985). Kinetic-properties of a sex pheromone-degrading enzyme - the sensillar esterase of antheraeapolyphemus. Proc. Natl. Acad. Sci. U.S.A. 82, 8827-8831. doi: 10.1073/pnas.82. 24.8827

von Arx, M., Schmidt-Busser, D., and Guerin, P. M. (2012). Plant volatiles enhance behavioral responses of grapevine moth males, Lobesia botrana to sex pheromone. J. Chem. Ecol. 38, 222-225. doi: 10.1007/s10886-012-0068-z

Wang, F., Deng, J., Schal, C., Lou, Y., Zhou, G., Ye, B., et al. (2016). Non-host plant volatiles disrupt sex pheromone communication in a specialist herbivore. Sci. Rep. 6:32666. doi: 10.1038/srep32666

Wang, Y. L., Xing, X., Zhao, H. B., Chen, Q., Luo, W. Q., and Ren, B. Z. (2016). Screening of essential oil antifeedants in the elm pest Ambrostoma quadriimpressum (Coleoptera: Chrysomelidae). Fla. Entomol. 99, 231-238. doi: $10.1653 / 024.099 .0212$
Xu, P., Atkinson, R., Jones, D. N. M., and Smith, D. P. (2005). Drosophila OBP LUSH is required for activity of pheromone-sensitive neurons. Neuron 45, 193-200. doi: 10.1016/j.neuron.2004.12.031

Xu, W., Cornel, A. J., and Leal, W. S. (2010). Odorant-binding proteins of the malaria mosquito Anopheles funestus sensu stricto. PLoS One 5:e15403. doi: 10.1371/journal.pone.0015403

Yi, S. Y., Li, D. Z., Zhou, C. X., Tang, Y. L., Abdelnabby, H. E., and Wang, M. Q. (2018). Screening behaviorally active compounds based on fluorescence quenching in combination with binding mechanism analyses of SspOBP7, an odorant binding protein from Sclerodermus sp. Int. J. Biol. Macromol. 107, 2667-2678. doi: 10.1016/j.ijbiomac.2017.10.149

Yin, J., Feng, H., Sun, H., Xi, J., Cao, Y., and Li, K. (2012). Functional analysis of general odorant binding protein 2 from the meadow moth, Loxostege sticticalis L. (Lepidoptera: Pyralidae). PLoS One 7:e33589. doi: 10.1371/journal.pone. 0033589

Zhang, J., Liu, C. C., Yan, S. W., Liu, Y., Guo, M. B., Dong, S. L., et al. (2013). An odorant receptor from the common cutworm (Spodoptera litura) exclusively tuned to the important plant volatile cis-3-hexenyl acetate. Insect Mol. Biol. 22, 424-432. doi: 10.1111/imb.12033

Zhu, J., Arena, S., Spinelli, S., Liu, D., Zhang, G., Wei, R., et al. (2017). Reverse chemical ecology: olfactory proteins from the giant panda and their interactions with putative pheromones and bamboo volatiles. Proc. Natl. Acad. Sci. U.S.A. 114, E9802-E9810. doi: 10.1073/pnas.1711437114

Zhu, J. Y., Zhao, N., and Yang, B. (2012). Global transcriptome profiling of the pine shoot beetle, Tomicus yunnanensis (Coleoptera: Scolytinae). PLoS One 7:e32291. doi: 10.1371/journal.pone.0032291

Zhuang, X., Wang, Q., Wang, B., Zhong, T., Cao, Y., Li, K., et al. (2014). Prediction of the key binding site of odorant-binding protein of Holotrichia oblita Faldermann (Coleoptera: Scarabaeida). Insect Mol. Biol. 23, 381-390. doi: $10.1111 /$ imb. 12088

Conflict of Interest Statement: The authors declare that the research was conducted in the absence of any commercial or financial relationships that could be construed as a potential conflict of interest.

Copyright (C) $2018 \mathrm{Ju}, \mathrm{Li}, \mathrm{Guo}, \mathrm{Du}$, Shi and Qu. This is an open-access article distributed under the terms of the Creative Commons Attribution License (CC BY). The use, distribution or reproduction in other forums is permitted, provided the original author(s) and the copyright owner(s) are credited and that the original publication in this journal is cited, in accordance with accepted academic practice. No use, distribution or reproduction is permitted which does not comply with these terms. 